\title{
Unexpected reactivity related to support effects during xylose hydrogenation over ruthenium catalysts
}

\author{
Léa Vilcocq, ${ }^{* a}$ Ana Paez, ${ }^{a}$ Victoria D. S. Freitas, ${ }^{a}$ Laurent Veyre, ${ }^{a}$ Pascal Fongarland ${ }^{a}$ and Régis \\ Philippe $^{\mathrm{a}}$
}

\begin{abstract}
Xylose is a major component of hemicelluloses. In this paper, its hydrogenation to xylitol in aqueous medium was investigated with two $\mathrm{Ru} / \mathrm{TiO}_{2}$ catalysts prepared with two commercial $\mathrm{TiO}_{2}$ supports. A strong impact of support on catalytic performances was evidenced. $\mathrm{Ru} / \mathrm{TiO}_{2}-\mathrm{R}$ led to fast and selective conversion of xylose $\left(100 \%\right.$ conversion in $2 \mathrm{~h}$ at $120^{\circ} \mathrm{C}$ with $99 \%$ selectivity) whereas $\mathrm{Ru} / \mathrm{TiO}_{2}-\mathrm{A}$ gave a slower and much less selective transformation ( $58 \%$ conversion in $4 \mathrm{~h}$ at $120^{\circ} \mathrm{C}$ with $17 \%$ selectivity) with the formation of several by-products. Detailed characterization of catalysts with ICP, XRD, FTIR, TEM, $\mathrm{H}_{2}$ chemisorption, $\mathrm{N}_{2}$ porosimetry, TPR and acid-base titration were performed to elucidate the role of each support. $\mathrm{TiO}_{2}-\mathrm{R}$ has a small specific surface area with large ruthenium nanoparticles in weak interaction with $\mathrm{TiO}_{2}$ support and no acidity, whereas $\mathrm{TiO}_{2}-\mathrm{A}$ is a mesoporous material with a large specific surface area, mildly acidic, and bears small ruthenium particles in strong interaction with $\mathrm{TiO}_{2}$ support. The former was very active and selective for xylose hydrogenation to xylitol whereas the latter was less active and poorly selective. Moreover, careful analysis of reaction products also revealed that $\mathrm{TiO}_{2}$ anatase can catalyze undesired side-reactions such as xylose isomerisation to various pentoses, and therefore the corresponding unexpected polyols (arabitol, ribitol) were produced during xylose conversion by hydrogenation. In a first approach of the kinetics, a simplified kinetic model was built to compare quantitatively intrinsic reaction rates of both catalysts. The kinetic constant for hydrogenation was 20 times higher for $\mathrm{Ru} / \mathrm{TiO}_{2}-\mathrm{R}$ at $120^{\circ} \mathrm{C}$.
\end{abstract}

\section{Introduction}

Biomass is a unique source of renewable carbon on our planet. In the current context of fossil resources depletion, increase in the world demand for fuels and chemicals, and global climate change due to $\mathrm{CO}_{2}$ emissions from fossil sources, the development of biobased chemicals appears critical for a sustainable future. Today, biobased chemistry represents 177 M€/year and 7.9 Mt/year in Europe, i.e. $35 \%$ of the chemical industry market and $10 \%$ of all carbon-based materials, without including biofuels nor food manufacture. As $85 \%$ of chemical compounds could be technically biosourced, European Union's target is 25 wt.\% of biosourced carbon-based materials in 2030. ${ }^{1}$

Lignocellulose, as the main constituent of fibrous plants (e.g. herbs, straws, trees), is a major source of biomass. It is constituted by three components: cellulose, a crystalline glucose homopolysaccharide, lignin, a phenolic macropolymer, and hemicellulose, an amorphous heteropolysaccharide. The latter represents 20 to $40 \mathrm{wt}$.\% of lignocellulose. ${ }^{2}$

Hemicellulose is a polymer of different sugars bearing six carbon atoms (hexoses, e.g. glucose, mannose, galactose) or five carbon atoms (pentoses, e.g. xylose, arabinose), arranged in linear and branched structures, in which acetyl groups can also be found. ${ }^{5}$ The composition of hemicelluloses varies with the type of biomass. For example, xylans are predominant in hardwood hemicelluloses. ${ }^{6}$

Xylose is the main ex-hemicellulose sugar from xylan. It is a starting material for various processes, and as such was identified as one of the Top 10 and then Top 12 platform biomolecules. 7,8 It is notably used to produce furfural, furan dicarboxylic acid (FDCA), $\gamma$-valerolactone (GVL), glycols, etc. However, the main industrial xylose-based process is the production of xylitol. This polyol is used in food industry and pharmaceutical industry as an additive and as a low calorie sweetener. Its market is evaluated ca. 300 kton/year. ${ }^{9}$ It is industrially produced by selective catalytic hydrogenation. Other polyols can be produced from pentoses, such as arabitol, from arabinose, lyxose or ribulose, and ribitol (also known as adonitol) from ribose or ribulose. Both arabitol and ribitol are used as pharmaceutical ingredients. ${ }^{10}$

Historically, Raney nickel was used as heterogeneous catalyst for the hydrogenation of glucose and xylose. ${ }^{11-13}$ Nickel is advantageous because of its low price, but can leach easily in aqueous phase and leads to toxicity issues. Thus, some authors tried to reduce $\mathrm{Ni}$ leaching from nickel catalysts. ${ }^{14-17} \mathrm{Ni}$ catalyst supported on nitrogen-doped carbon was used for $40 \mathrm{~h}$ presenting high catalytic activity. Although, high temperatures (ca. $150^{\circ} \mathrm{C}$ ) were necessary to obtain high xylitol yields. ${ }^{16}$ Bimetallic catalysts were also used in literature. ${ }^{17-19}$ The use of Sn associated to Pt was beneficial to the conversion and selectivity of the catalyst to xylitol synthesis. Thus, the increase of $\mathrm{Sn}$ amount in catalyst favoured by-products synthesis. ${ }^{18}$ Aiming to reduce the catalyst deactivation, $\mathrm{Ni}$ was used associated with Re. Both monometallic and bimetallic catalysts presented $\mathrm{Ni}$ leaching in reaction media, but the presence of Re decreased this deactivation, helping to increase catalyst stability. ${ }^{17}$ However, few catalysts presented high catalytic activity associated to high selectivity towards sugar alcohols. $\mathrm{Ru} / \mathrm{C}$ is today the main catalyst for xylose hydrogenation at laboratory scale. ${ }^{13}$ Indeed, ruthenium is an oxophilic metal particularly active for aqueous phase hydrogenation of carbonyl groups. ${ }^{20}$ It presents a catalytic activity superior to other metals in the xylose hydrogenation reaction, in the following the order: $\mathrm{Ru}>\mathrm{Ni} \approx \mathrm{Co}>\mathrm{Pt}>\mathrm{Rh} \approx \mathrm{Pd} .{ }^{11,21}$ Its price is also interesting for industrial applications, as ruthenium is much less expensive than palladium or platinum. ${ }^{22}$

The choice of supports is critical for such an aqueous phase reaction, as water can induce several deactivation phenomena such as leaching, phase changes through hydration, collapsing of porous structures, etc. Few candidates have been identified as stable supports in water: carbon materials, titanium dioxide $\left(\mathrm{TiO}_{2}\right)$, zirconium dioxide $\left(\mathrm{ZrO}_{2}\right) .{ }^{23}$ Among them, $\mathrm{TiO}_{2}$ has the 
property to assist $\mathrm{H}_{2}$ activation via a spillover phenomenon ${ }^{24}$ and is thus a promising support for ruthenium in aqueous phase hydrogenation reactions. $\mathrm{TiO}_{2}$ can exist in several crystalline phases but the most common for catalysis applications are anatase and rutile.

$\mathrm{Ru} / \mathrm{TiO}_{2}$ was already studied for xylose and glucose hydrogenation reactions ${ }^{14,25,26}$ but the impact of support properties, such as crystalline phase, was reported in only one article so far. Hernandez-Mejia et al compared the activities of $\mathrm{Ru} / \mathrm{TiO}_{2}$ catalysts with different $\mathrm{TiO}_{2}$ supports from $100 \%$ anatase to $100 \%$ rutile and observed a higher yield of xylitol when rutile was present. ${ }^{27}$ In their experimental conditions, $\mathrm{TiO}_{2}$ rutile lead to smaller ruthenium nanoparticles during catalyst synthesis. Therefore, they attributed the higher activity in xylose hydrogenation to the higher number of surface ruthenium atoms, i.e. the catalytic sites, on the catalyst surface. However, they did not explain the decrease of selectivity observed with $\mathrm{TiO}_{2}$ anatase as a support nor identify reaction by-products. The decrease of activity for $\mathrm{TiO}_{2}$ anatase was interpreted only as a consequence of low ruthenium dispersion on the support.

The impact of $\mathrm{TiO}_{2}$ support on ruthenium particle size was also described for other catalytic applications, but contradictory results were obtained. For example, Zhang et al observed smaller ruthenium nanoparticles on $\mathrm{TiO}_{2}$ anatase than on $\mathrm{TiO}_{2}$ rutile, ${ }^{24}$ whereas other authors observed smaller ruthenium nanoparticles and a more homogeneous repartition of nanoparticles on $\mathrm{TiO}_{2}$ rutile. ${ }^{27-30}$

In this paper, the impact of $\mathrm{TiO}_{2}$ support on the reactivity of ruthenium catalysts in xylose hydrogenation was investigated with a focus on the differences in reactivity observed when different supports are used. Two catalysts with two different commercial $\mathrm{TiO}_{2}$, anatase and rutile, were prepared, characterized and tested for xylose hydrogenation. Xylose conversion and the production of xylitol and other by-products were studied to understand the role of each support on the behaviour of $\mathrm{Ru} / \mathrm{TiO}_{2}$ catalysts.

\section{Experimental}

\section{Materials}

Ruthenium (III) chloride $\left(\mathrm{RuCl}_{3} \times \mathrm{xH}_{2} \mathrm{O}\right)$ and xylose were purchased from Sigma-Aldrich and xylitol was purchased from Acros Organics with purity higher than $98 \%$. Two $\mathrm{TiO}_{2}$ supports were used: $\mathrm{TiO}_{2}$ anatase with high specific surface area from Alfa Aesar (CAS 1317-70-0, reference 44429) and $\mathrm{TiO}_{2}$ rutile from Sigma Aldrich (CAS 1317-80-2, reference 224227). All the materials were used without further purification.

\section{Catalyst preparation}

The catalysts were prepared by incipient wetness impregnation. $\mathrm{TiO}_{2}$ was crushed in powder, sieved below $90 \mu \mathrm{m}$, and dried $2 \mathrm{~h}$ at $120^{\circ} \mathrm{C}$. The precursor solution was prepared using a volume of ethanol necessary to wet the support and the appropriate amount of $\mathrm{RuCl}_{3} \cdot \mathrm{xH}_{2} \mathrm{O}$. The solution was added drop by drop to the dry support until the formation of a homogenous paste. Finally, this paste was dried overnight at $120^{\circ} \mathrm{C}$ and crushed afterward. The powder was calcined at $250^{\circ} \mathrm{C}$ under $\mathrm{N}_{2}$ flow and reduced at $350^{\circ} \mathrm{C}$ under $\mathrm{H}_{2}$ flow in a tubular oven. The corresponding catalysts were named $\mathrm{Ru} / \mathrm{TiO}_{2}-\mathrm{A}$ and $\mathrm{Ru} / \mathrm{TiO}_{2}-\mathrm{R}$.

\section{Catalyst characterization}

X-ray diffraction (XRD) was performed at Centre de Diffraction Henri Longchambon (CDHL) on a diffractometer Bruker D8 Advance with $2 \theta$ until $90^{\circ}$.

Infrared (IR) was performed at IRCELYON in absorbance mode using a Vector 22 apparatus on a Nicolet IS5 equipped with an ID7-ATR accessory with diamond crystal from Thermo Scientific with a spectral range of $4000 \mathrm{~cm}^{-1}$ to $525 \mathrm{~cm}^{-1}$.

$\mathrm{N}_{2}$ physisorption was performed on a Micrometrics ASAP 2010 apparatus at $-196^{\circ} \mathrm{C}$; samples were pre-treated at $350^{\circ} \mathrm{C}$ under vacuum for 4 hours before physisorption.

The acid site concentration in water of each catalyst was measured using a potentiometric titration following the method described by Yu et al. ${ }^{31}$ Briefly, $250 \mathrm{mg}$ of catalyst was dried at $120^{\circ} \mathrm{C}$ and then was stirred at room temperature in 50 $\mathrm{mL}$ of a $0.1 \mathrm{M} \mathrm{NaCl}$ solution under sparging $\mathrm{N}_{2}$. The suspension was titrated by a $\mathrm{NaOH} 0.1 \mathrm{M}$ solution using a Mettler Toledo G20S titrator equipped with a DGI 115 SC electrode. Three equivalence points were determined for $\mathrm{TiO}_{2}-\mathrm{A}$ and only one for $\mathrm{TiO}_{2}-\mathrm{R}$. At each equivalence point, a pKa and an acid sites concentration were determined using the Gran plot method. ${ }^{31-}$ 33

ICP analysis was performed by two external laboratories (IRCELYON and SOCOR) after mineralization of catalysts in a closed vessel.

Hydrogen chemisorption studies were carried out in a BELJAPAN BELSORP-max system. In each analysis, $c a$. $0.4 \mathrm{~g}$ of $\mathrm{Ru} / \mathrm{TiO}_{2}$ catalyst was used. The sample was first reduced under $\mathrm{H}_{2}$ flow at $350^{\circ} \mathrm{C}$ for $3 \mathrm{~h}\left(\mathrm{ramp}\right.$ of $\left.3^{\circ} \mathrm{C} \cdot \mathrm{min}^{-1}\right)$. After reduction, the sample was evacuated at $350^{\circ} \mathrm{C}$ for $3 \mathrm{~h}$. The chemisorption measurements were performed at $75^{\circ} \mathrm{C}$. The number of available $\mathrm{Ru}$ atoms $\left(\mathrm{Ru}_{\mathrm{A}}\right)$ was calculated from total adsorption of $\mathrm{H}_{2}$ with a stoichiometry $\mathrm{H}: \mathrm{Ru}$ equal to $2: 1 .^{34}$

$$
R u_{A}\left(\mu \mathrm{mol} . g^{-1}\right)=\frac{n\left(H_{2} \text { total, } \mu \mathrm{mol}\right)}{m_{\text {cat }}(g)}
$$

STEM-HAADF (Scanning Transmission Electronic Microscopy High Angle Annular Dark Field) images were taken by a JEOL $2100 \mathrm{~F}$ microscope, with a $200 \mathrm{kV}$ acceleration tension. These characterizations were performed at "Centre Technologique des Microstructures" (CT $\mu$, Villeurbanne, France). Samples were dispersed in ethanol using ultrasound prior the deposition of a few drops on holey carbon films on copper grids. Histograms and mean particle diameters were determined with 200 counts with ImageJ software.

Temperature programmed reduction (TPR) was performed in a TPD/R/O 1110 Catalytic Surfaces Analyzer apparatus from Thermo Scientific equipped with a TCD detector and a cold trap to remove water before detection. The sample of $\mathrm{Ru} / \mathrm{TiO}_{2}$ catalyst was pre-oxidized $30 \mathrm{~min}$ at $200^{\circ} \mathrm{C}$ under $5 \% \mathrm{O}_{2} / \mathrm{He}$ flow, swiped with pure $\mathrm{He}$ at room temperature for $30 \mathrm{~min}$ and reduced under $5 \% \mathrm{H}_{2} / \mathrm{Ar}$ from room temperature to $800^{\circ} \mathrm{C}$. 


\section{Catalytic hydrogenation}

The catalytic hydrogenation of xylose was performed in a 120 $\mathrm{mL}$ Top Industrie autoclave stirred tank reactor heated by an electrical jacket and equipped with a gas-inducing Rushton turbine and four baffles. The reactor is thermo-regulated and when necessary cooling is ensured by a Ranque-Hilsch vortex device. The reactor is operated in batch mode for liquid (and solid) phase and semi-batch mode for the gas phase. In order to work at constant pressure, $\mathrm{H}_{2}$ contained in a pressurised gas tank was continuously added in the reactor via a pressure regulator. $80 \mathrm{~mL}$ of $50 \mathrm{~g} . \mathrm{L}^{-1}$ xylose solution $(0.33 \mathrm{M})$ and $1.2 \mathrm{~g}$ of catalyst (molar ratio $\mathrm{Ru} / x y$ lose of $0.45 \mathrm{~mol} . \%$ ) were introduced in the reactor, which was closed and purged with $\mathrm{N}_{2}$ before heating to the reaction temperature. Time zero was determined as the moment when the reaction mixture reached the programmed temperature and the reactor was pressurized with 40 bar $\mathrm{H}_{2}$. Samples were taken regularly through a sampling valve and filtered with $0.2 \mu \mathrm{m}$ syringe filters. The absence of external mass transfer limitations at $1600 \mathrm{rpm}$ stirring rate was verified experimentally by varying the stirring rate (ESI - Fig S1) and the absence of internal mass transfer limitations was evaluated through estimations of the Weisz-Prater criterion (see ESI for more details).

\section{Analytical methods}

HPLC analysis was performed on a Shimadzu apparatus equipped with a RID detector and a Phenomenex Rezex RPM column at $80^{\circ} \mathrm{C}$ with pure filtered water as a mobile phase, 0.6 $\mathrm{mL}$. $\mathrm{min}^{-1}$. Additionally, a Phenomenex Rezex ROA column and a Phenomenex Rezex RCM column at $50^{\circ} \mathrm{C}$ with acidified water (0.005 $\mathrm{N} \mathrm{H}_{2} \mathrm{SO}_{4}$ ) were used to confirm the identification of sugars and polyols by comparison with retention times of commercial standards. External calibration with four levels was used for quantification of sugars and polyols. Typical chromatograms are presented in ESI - Fig S2. The catalytic tests were duplicated and relative errors values were calculated from the HPLC analysis results and represented below as error bars. The following calculations were used in this work, based on concentrations in mol. $\mathrm{L}^{-1}$ :

$$
\text { Conversion }(\text { mol\% })=\frac{[\text { Xylose }]_{0}-[\text { Xylose }]_{t}}{[\text { Xylose }]_{0}}
$$

$$
\begin{gathered}
\text { Yield }(\text { mol\% })=\frac{[\text { Product }]_{t}}{[\text { Xylose }]_{0}} \\
\text { Selectivity }(\text { mol\% })=\frac{[\text { Product }]_{t}}{[\text { Xylose }]_{0}-[\text { Xylose }]_{t}} \\
\text { Carbon balance }(\%)=\frac{\sum_{i}\left([\text { Compound } i]_{t} \times N_{C}^{i} \times M_{C}\right)}{[\text { Xylose }]_{t} \times N_{C}^{x y l o s e} \times M_{C}}
\end{gathered}
$$

With initial concentration and concentration at time t $\left(\mathrm{mol}^{\mathrm{L}} \mathrm{L}^{-1}\right)$, $N_{C}^{i}$ atoms is the number of carbon atoms, $M_{C}$ is the molar mass of carbon (12 g.mol-1). Product can be Xylitol or other byproducts (Lyxose, Xylulose, Ribulose, Ribitol or Arabitol). Compound can be Xylose, Xylitol or other by-products (Lyxose, Xylulose, Ribulose, Ribitol or Arabitol).

Calculations of kinetic constants, energy of activation (Ea) and Turn-Over Frequency (TOF) are detailed in ESI.

\section{Results and discussion}

\section{Catalysts preparation and characterization}

$\mathrm{Ru} / \mathrm{TiO}_{2}$ catalysts were prepared by incipient wetness impregnation followed by calcination under $\mathrm{N}_{2}$ and reduction under $\mathrm{H}_{2}$ and characterised by several techniques (Table 1). $\mathrm{Ru}$ loading was verified after preparation by ICP analysis. For $\mathrm{Ru} / \mathrm{TiO}_{2}-\mathrm{A}$, a value of $0.9 \mathrm{wt}$.\%Ru was found and for $\mathrm{Ru} / \mathrm{TiO}_{2}-\mathrm{R}$, a value of $0.6 \mathrm{wt} . \%$ Ru was found.

XRD analysis shows that in $\mathrm{Ru} / \mathrm{TiO}_{2}-\mathrm{A}$, the support is a pure anatase phase with $11 \mathrm{~nm}$ mean crystallite size whereas in $\mathrm{Ru} / \mathrm{TiO}_{2}-\mathrm{R}$, the support is made of bigger mean crystallite size $(228 \mathrm{~nm}$ ) and contains some anatase impurities (6 \%) (ESI - Fig S5). The diffraction peak intensities are much higher for $\mathrm{TiO}_{2}-\mathrm{R}$ than for $\mathrm{TiO}_{2}-\mathrm{A}$, revealing higher degree of crystallinity, in accordance with the crystal sizes measured. Ruthenium is not visible on both diffractograms, probably because of its low loading on each support. 


\begin{tabular}{|c|c|c|c|}
\hline \multicolumn{2}{|r|}{ Catalyst } & \multirow{2}{*}{$\frac{\mathbf{R u} / \mathrm{TiO}_{2}-\mathbf{A}}{100 \% \text { anatase }}$} & \multirow{2}{*}{$\frac{\mathbf{R u} / \mathrm{TiO}_{\mathbf{2}}-\mathbf{R}}{94 \% \text { rutile }-6 \% \text { anatase }}$} \\
\hline XRD & Crystalline phase & & \\
\hline ICP-OES & Ru loading (wt.\%) & $0.86 \pm 0.03$ & $0.61 \pm 0.07$ \\
\hline \multirow[t]{3}{*}{ Physisorption } & BET specific surface area $\left(\mathrm{m}^{2} \cdot \mathrm{g}^{-1}\right)$ & $122 \pm 12$ & $2 \pm 0.2$ \\
\hline & Pore volume (mL.g ${ }^{-1}$ ) & $0.45 \pm 0.05$ & $0.01 \pm 0.001$ \\
\hline & Mean pore size* $(\mathrm{nm})$ & $11 \pm 1$ & n.d. \\
\hline \multirow[t]{3}{*}{ FTIR } & IR bands & $1625 \mathrm{~cm}^{-1}$ ( $\mathrm{H}_{2} \mathrm{O}$-ads) & Weak $3300 \mathrm{~cm}^{-1}(v(\mathrm{O}-\mathrm{H}))$ \\
\hline & & $3300 \mathrm{~cm}^{-1}(v(\mathrm{O}-\mathrm{H}))$ & $400-500 \mathrm{~cm}^{-1}(v(\mathrm{Ti}-\mathrm{O}-\mathrm{Ti}))$ \\
\hline & & $400-500 \mathrm{~cm}^{-1}(v(\mathrm{Ti}-\mathrm{O}-\mathrm{Ti}))$ & \\
\hline \multirow[t]{2}{*}{ TEM } & Ru nanoparticles & $\begin{array}{l}\text { Small nanoparticles, homogeneously } \\
\text { dispersed. }\end{array}$ & $\begin{array}{l}\text { Heterogeneous dispersion, from } 1 \mathrm{~nm} \text { to } \\
100 \mathrm{~nm} \text {, presence of aggregates. }\end{array}$ \\
\hline & & $2.4 \mathrm{~nm}$ mean diameter & 12.5 mean diameter \\
\hline $\mathrm{H}_{2}$ Chemisorption & $\begin{array}{l}\text { Ru accessibility (number of available } \\
\qquad \text { Ru atoms, } R u_{A} \text { ) }\end{array}$ & $8.61 \mu \mathrm{mol} . \mathrm{g}^{-1}$ & $8.99 \mu \mathrm{mol} . \mathrm{g}^{-1}$ \\
\hline
\end{tabular}

*Calculated using the BJH method

$\mathrm{N}_{2}$ physisorption isotherm of $\mathrm{Ru} / \mathrm{TiO}_{2}-\mathrm{A}$ (ESI - Fig S6) corresponds to a type IV isotherm with $\mathrm{H} 3$ hysteresis loop typical of mesoporous materials with disordered pore network. ${ }^{35}$ For $\mathrm{Ru} / \mathrm{TiO}_{2}-\mathrm{R}$, the isotherm shape corresponds to minor condensation of $\mathrm{N}_{2}$ in mesopores and major condensation in inter-particles void (mix of Type IV and Type II isotherms), thus indicating a mostly non porous material. The specific BET surface area of $\mathrm{TiO}_{2}-\mathrm{A}$ is high (more than $100 \mathrm{~m}^{2} \cdot \mathrm{g}$ 1) compared to $\mathrm{TiO}_{2}-\mathrm{R}$ (less than $2 \mathrm{~m}^{2} \cdot \mathrm{g}^{-1}$ ). The mean pore diameter of $\mathrm{TiO}_{2}-\mathrm{A}$ is $11 \mathrm{~nm}$ (Table 1), largely superior to the hydrodynamic radius of sugars, estimated to be lower than $4 \AA$ for xylose. ${ }^{36,37}$

Hence, both supports exhibit very different bulk properties. FTIR was used to characterize surface groups of both catalysts (Figure 1). Three main bands can be observed on FTIR spectra of catalysts: broad stretching band corresponding to surface $\mathrm{O}$ $\mathrm{H}$ bonds around $3300 \mathrm{~cm}^{-1}$, a small band at $1625 \mathrm{~cm}^{-1}$ corresponding to adsorbed water, and an intense band between 400 and $500 \mathrm{~cm}^{-1}$ corresponding to Ti-O-Ti stretching bond. ${ }^{38,39}$ Spectra corresponding to $\mathrm{TiO}_{2}$ and corresponding to $\mathrm{Ru} / \mathrm{TiO}_{2}$ are identical. However, the comparison of $\mathrm{TiO}_{2}-\mathrm{A}$ and $\mathrm{TiO}_{2}-\mathrm{R}$ spectra shows some differences: the band corresponding to adsorbed water at $1625 \mathrm{~cm}^{-1}$ is only visible on $\mathrm{TiO}_{2}-\mathrm{A}$, indicating that this support is more favourable to water adsorption, i.e. is more polar; the band corresponding to $\mathrm{O}-\mathrm{H}$ group is also more intense on $\mathrm{TiO}_{2}-\mathrm{A}$. The band corresponding to $\mathrm{Ti}-\mathrm{O}-\mathrm{Ti}$ is present on both spectra. The presence of $-\mathrm{OH}$ groups on anatase and rutile was described in the early 1970's by Primet et al. ${ }^{40}$ It was demonstrated that these groups could have a weak basic or a medium acidic behaviour. Moreover, electronic vacancies on the surface of $\mathrm{TiO}_{2}$, and particularly on $\mathrm{TiO}_{2}$ anatase, creates strong Lewis acid sites, which can also form Brønsted acid sites in the presence of adsorbed water. ${ }^{38,41}$

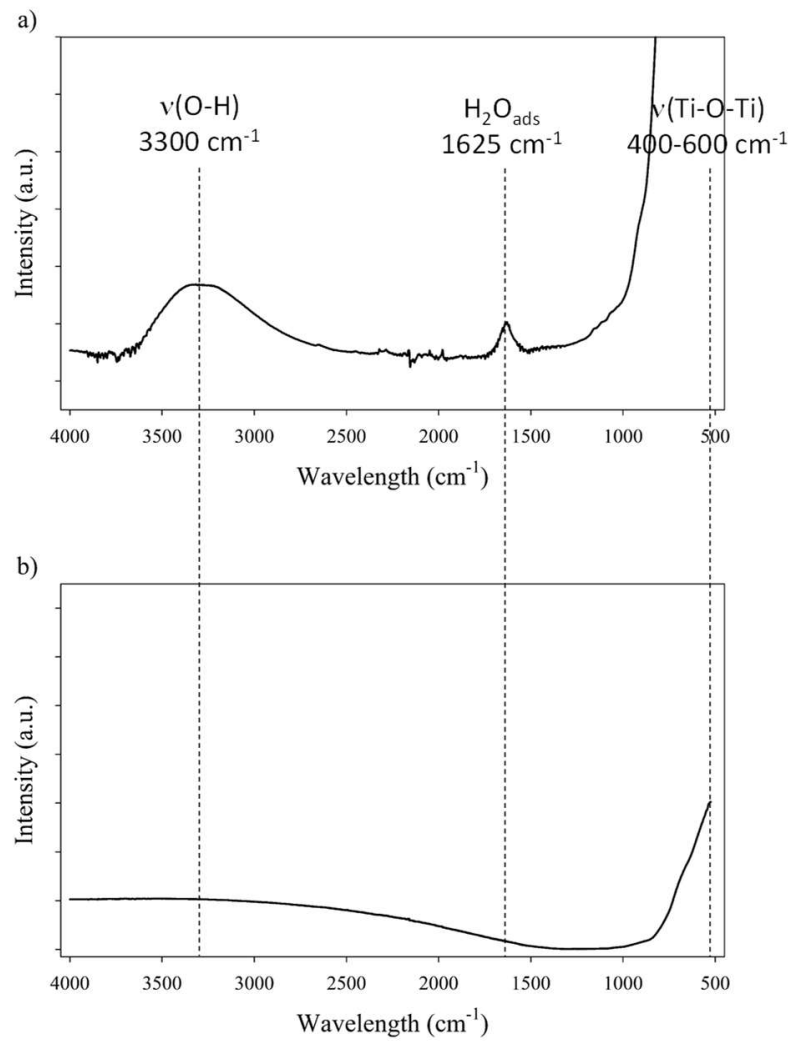

Figure 1. FTIR spectra of $\mathrm{Ru} / \mathrm{TiO}_{2}-\mathrm{A}(\mathrm{a})$ and $\mathrm{Ru} / \mathrm{TiO}_{2}-\mathrm{R}(\mathrm{b})$.

Potentiometric titration of $\mathrm{TiO}_{2}-\mathrm{A}$ and $\mathrm{TiO}_{2}-\mathrm{R}$ supports was performed to evaluate their acidity. This method has the advantage to measure acid sites in the presence of liquid water, therefore in environmental conditions close to the reaction. $\mathrm{TiO}_{2}-\mathrm{A}$ exhibited 3 different types of acid sites with different strengths. The most numerous ones are the weaker ones, with a concentration of $249 \mu \mathrm{mol} . \mathrm{g}^{-1}$ and pKa 9.3. Stronger acid sites with a concentration of $152 \mu \mathrm{mol} . \mathrm{g}^{-1}$ and pKa 8.6 and then 
concentration of $152 \mu \mathrm{mol} . \mathrm{g}^{-1}$ and pKa 6.2 were also detected. On the contrary, $\mathrm{TiO}_{2}-\mathrm{R}$ only bears acid sites with pKa 8.6 in a concentration of $27 \mu \mathrm{mol} . \mathrm{g}^{-1}$.

These results are in agreement with the analysis of acid sites in gas phase described in literature: 41 anatase bears medium Brønsted acid sites and strong Lewis acid sites and rutile is much less acidic than anatase. In total, $\mathrm{Ru} / \mathrm{TiO}_{2}-\mathrm{A}$ holds $466 \mu \mathrm{mol} . \mathrm{g}^{-1}$ and $\mathrm{TiO}_{2}-\mathrm{R} 27 \mathrm{\mu mol}^{-1}$ acid sites. Both supports have very different specific surface area, as stated before. The density of acid sites on this surface is $3.8 \mu \mathrm{mol} . \mathrm{m}^{-2}$ for $\mathrm{TiO}_{2}-\mathrm{A}$ and 13 $\mu \mathrm{mol} . \mathrm{m}^{-2}$ for $\mathrm{TiO}_{2}-\mathrm{R}$, evidencing that the acidity of $\mathrm{TiO}_{2}-\mathrm{A}$ support is mainly a consequence of its large specific surface area.
Table 2. Acidity of $\mathrm{TiO}_{2}-\mathrm{A}$ and $\mathrm{TiO}_{2}-\mathrm{R}$ supports.

\begin{tabular}{|c|c|c|}
\hline Support & $\mathrm{TiO}_{2}-\mathrm{A}$ & $\mathrm{TiO}_{2}-\mathrm{R}$ \\
\hline \multicolumn{3}{|l|}{ Weak acid sites } \\
\hline Concentration $\left(\mu \mathrm{mol} \mathrm{eqH}_{\left.\mathrm{H} \cdot \mathrm{g}^{-1}\right)}\right.$ & 249.67 & - \\
\hline$p K a$ & 9.3 & - \\
\hline \multicolumn{3}{|l|}{ Medium acid sites } \\
\hline Concentration $\left(\mu \mathrm{mol}_{\text {eqH+. }} \mathrm{g}^{-1}\right)$ & 152.59 & 27.18 \\
\hline$p K a$ & 8.6 & 8.6 \\
\hline \multicolumn{3}{|l|}{ Strong acid sites } \\
\hline Concentration $\left(\mu \mathrm{mol} \mathrm{eqH}_{\mathrm{H} .} \mathrm{g}^{-1}\right)$ & 63.35 & - \\
\hline$p K a$ & 6.2 & - \\
\hline \multicolumn{3}{|l|}{ Total acid sites } \\
\hline Concentration $\left(\mu \mathrm{mol}_{\mathrm{eqH}+\cdot} \mathrm{g}^{-1}\right)$ & 465.61 & 27.18 \\
\hline
\end{tabular}

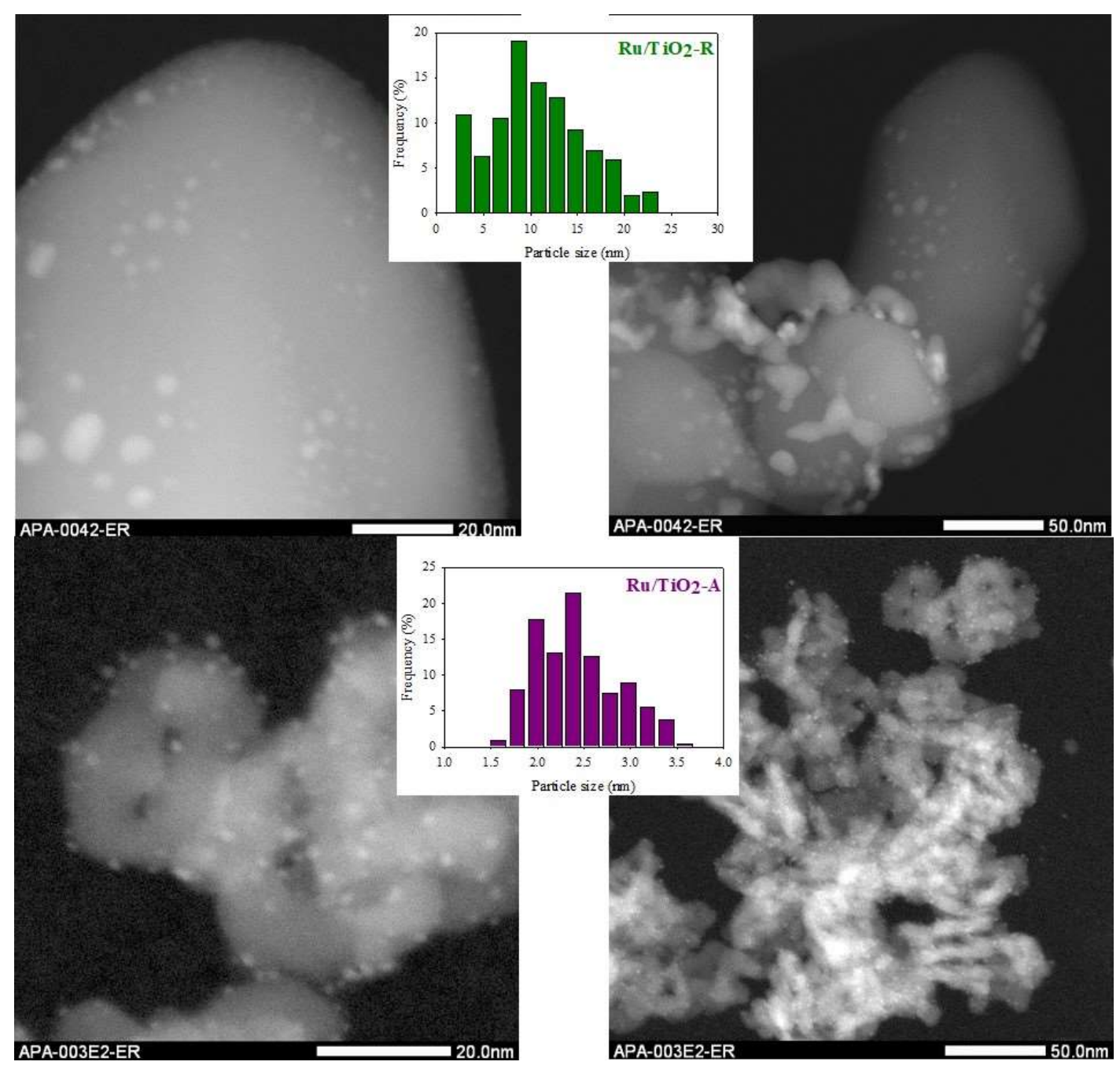

Figure 2. TEM pictures of $\mathrm{Ru} / \mathrm{TiO}_{2}-\mathrm{R}$ (up) and $\mathrm{Ru} / \mathrm{TiO}_{2}-\mathrm{A}$ (down), with the corresponding histograms of Ru nanoparticles size. 
Given these differences in supports properties, one could expect different dispersions of ruthenium and different metalsupport electronic interactions on each $\mathrm{TiO}_{2}$ support. Concerning metal dispersion, STEM analysis revealed major differences between both catalysts (Figure 2, Table 1). $\mathrm{Ru} / \mathrm{TiO}_{2^{-}}$ A exhibits small nanoparticles, visible as white nanospheres on the gray support, with a homogeneous dispersion in size and on the support. On the contrary, $\mathrm{Ru} / \mathrm{TiO}_{2}-\mathrm{R}$ exhibits a larger range of particle sizes, from small nanoparticles to large aggregates. The dispersion on $\mathrm{TiO}_{2}-\mathrm{R}$ support is very heterogeneous with large zones of support where ruthenium is absent and small zones with a high density of ruthenium, as shown by EDX mapping on Fig S7 (ESI). Histogram of nanoparticles is centred on 2-2.5 nm for $\mathrm{Ru} / \mathrm{TiO}_{2}-\mathrm{A}$, with $2.4 \mathrm{~nm}$ mean diameter, and on 7-9 $\mathrm{nm}$ for $\mathrm{Ru} / \mathrm{TiO}_{2}-\mathrm{R}$, with $12.5 \mathrm{~nm}$ mean diameter.

TPR analysis was performed on pre-oxidised samples of both $\mathrm{Ru} / \mathrm{TiO}_{2}$ catalysts (Figure 3 ). Different reduction profiles were observed. For $\mathrm{Ru} / \mathrm{TiO}_{2}-\mathrm{R}$, a first peak was observed at $89^{\circ} \mathrm{C}$, corresponding to $\mathrm{RuO}_{2}$ that have no interaction with the support ${ }^{30}$ and a second smaller and broader peak around $150^{\circ} \mathrm{C}$ corresponds to $\mathrm{RuO}_{x}$ in strong interaction with $\mathrm{TiO}_{2} \cdot{ }^{30}$ Therefore, for $\mathrm{Ru} / \mathrm{TiO}_{2}-\mathrm{R}$ catalyst, $\mathrm{RuO}_{2}$ would correspond to large $\mathrm{Ru}$ particles and represent $68 \%$ of reductible species and $\mathrm{RuO}_{\mathrm{x}}$ corresponding to small particles in strong interaction with support corresponds to $32 \%$ of reductible species. For $\mathrm{Ru} / \mathrm{TiO}_{2}-$ $A$, two reduction peaks are visible at low temperature $\left(57^{\circ} \mathrm{C}\right.$ and $88^{\circ} \mathrm{C}$ ) and a large, broader peak centred around $320^{\circ} \mathrm{C}$. The latter represents $56 \%$ of reducible species on the sample. Peaks at low temperature should be similar to $\mathrm{RuO}_{2}$ species observed on $\mathrm{Ru} / \mathrm{TiO}_{2}-\mathrm{R}$ whereas the peak at high temperature is an indication of $\mathrm{RuO}_{\mathrm{x}}$ nanoparticles as the dominant $\mathrm{Ru}$ species. The difference in temperature reduction for $\mathrm{RuO}_{x}$ species between both catalysts $\left(+170^{\circ} \mathrm{C}\right.$ for $\left.\mathrm{Ru} / \mathrm{TiO}_{2}-\mathrm{A}\right)$ shows that metal-support interactions are much stronger on $\mathrm{Ru} / \mathrm{TiO}_{2}-\mathrm{A}$ than on $\mathrm{Ru} / \mathrm{TiO}_{2}-\mathrm{R}$.

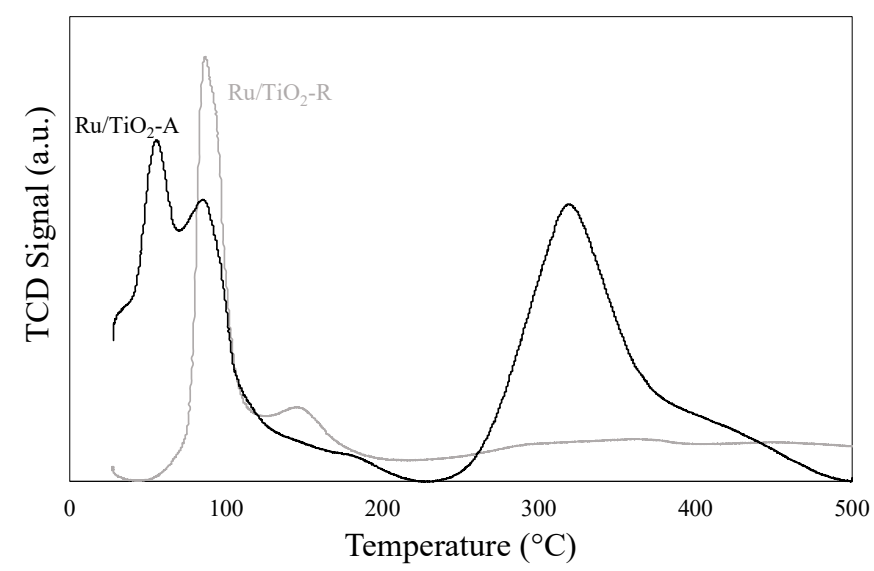

Figure 3. Reduction profiles of $\mathrm{Ru} / \mathrm{TiO}_{2}$ catalysts.

In summary, $\mathrm{TiO}_{2}-\mathrm{A}$ and $\mathrm{TiO}_{2}-\mathrm{R}$ supports differs by their physical-chemical properties. $\mathrm{TiO}_{2}-\mathrm{A}$ is a mesoporous material with relatively high specific surface area, the main crystalline phase is anatase, with a low crystallinity. This support contains acidic sites, which could correspond to Lewis acid sites $\mathrm{Ti}^{4+}$ on
$\mathrm{TiO}_{2}$ surface. On the other hand, $\mathrm{TiO}_{2}-\mathrm{R}$ is a poorly porous material with low specific surface area; the main crystalline phase is rutile, with a high crystallinity and quite neutral surface properties. Ruthenium impregnation on both supports gave different catalysts. $\mathrm{Ru} / \mathrm{TiO}_{2}-\mathrm{A}$ holds small, homogeneously dispersed Ru nanoparticles, most of them in strong interaction with $\mathrm{TiO}_{2}$ support, but the amount of surface ruthenium atoms able to activate $\mathrm{H}_{2}$ is low. $\mathrm{Ru} / \mathrm{TiO}_{2}-\mathrm{R}$ bears also small nanoparticles in strong interaction with $\mathrm{TiO}_{2}$ support (although this interaction is weaker than for $\mathrm{Ru} / \mathrm{TiO}_{2}-\mathrm{A}$ ) and larger aggregates with weak metal-support interaction and with a heterogeneous dispersion; the amount of surface ruthenium atoms able to activate $\mathrm{H}_{2}$ corresponds to the dispersion of ruthenium observed by microscopy. Finally, the amount of available ruthenium atoms $\left(R u_{A}\right)$ is similar for both catalysts: $8.99 \mu \mathrm{mol} . \mathrm{g}^{-1}$ and $8.61 \mu \mathrm{mol} . \mathrm{g}^{-1}$ for $\mathrm{Ru} / \mathrm{TiO}_{2}-\mathrm{R}$ and $\mathrm{Ru} / \mathrm{TiO}_{2}-\mathrm{A}$, respectively. Normalized with the specific surface area of each support, the surface density of ruthenium atoms is $4.2 \times 10^{17}$ Ru. $\mathrm{m}^{-2}$ for $\mathrm{Ru} / \mathrm{TiO}_{2}-\mathrm{A}$ and $18 \times 10^{19} \mathrm{Ru} . \mathrm{m}^{-2}$ for $\mathrm{Ru} / \mathrm{TiO}_{2}-\mathrm{R}$, based on ruthenium content, which explains that ruthenium was much more easily dispersed in small nanoparticles on $\mathrm{TiO}_{2}-\mathrm{A}$ than on $\mathrm{TiO}_{2}-\mathrm{R}$, resulting in smaller nanoparticles in the former case. On the contrary, the density of active ruthenium atoms $\left(\mathrm{Ru}_{\mathrm{A}}\right.$, as measured by chemisorption) is $7.3 \times 10^{8} \mathrm{Ru} \cdot \mathrm{m}^{-2}$ for $\mathrm{Ru}_{\mathrm{A}} / \mathrm{TiO}_{2}-\mathrm{A}$ and $4.3 \times 10^{6}$ Ru.m ${ }^{-2}$ for $\mathrm{Ru}_{\mathrm{A}} / \mathrm{TiO}_{2}-\mathrm{R}$. It can be concluded that on the large surface area of $\mathrm{TiO}_{2}-\mathrm{A}$, the availability of ruthenium is limited, because of strong metalsupport interactions. 


\section{Xylose hydrogenation over $\mathrm{Ru} / \mathrm{TiO}_{2}$ catalysts}

Xylose hydrogenation over $\mathrm{Ru} / \mathrm{TiO}_{2}-\mathrm{R}$ at $120^{\circ} \mathrm{C}$ produced xylitol with $100 \%$ selectivity (Figure $4 a$ ). The conversion was complete after $2 \mathrm{~h}$. No xylitol degradation was observed after the end of the reaction.

On the contrary, xylose hydrogenation over $\mathrm{Ru} / \mathrm{TiO}_{2}$-A led to 61 $\%$ conversion after $4 \mathrm{~h}$, indicating a reaction rate much lower than for $\mathrm{Ru} / \mathrm{TiO}_{2}-\mathrm{R}$ (Figure $4 \mathrm{~b}$ ). Xylitol was produced with low selectivity around $52 \%$ at $10 \%$ conversion and decreasing to 17 $\%$ at $60 \%$ of conversion. This continuous decay in selectivity with increasing conversion seems to indicate that the catalyst favours side-reactions producing unexpected by-products.
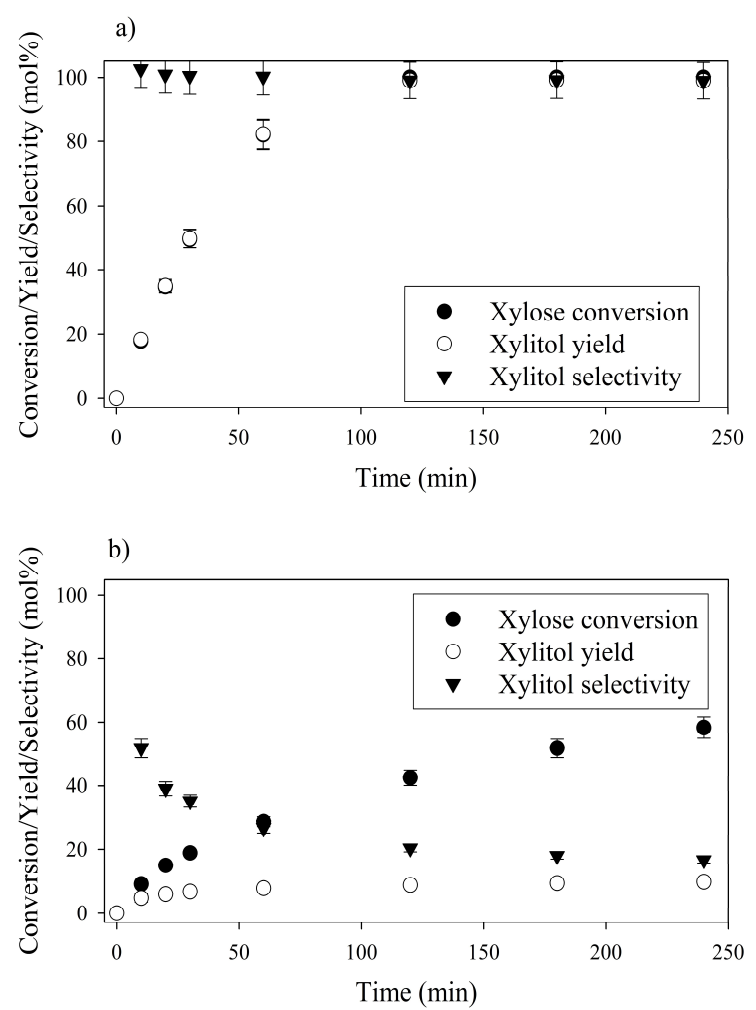

Figure 4. Xylose hydrogenation over $\mathrm{Ru} / \mathrm{TiO}_{2}-\mathrm{R}$ (a) and $\mathrm{Ru} / \mathrm{TiO}_{2}-\mathrm{A}$ (b). Reaction conditions:

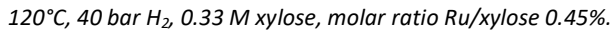

Moreover, in a comparable blank experiment, the supports were tested without ruthenium. $\mathrm{TiO}_{2}-\mathrm{R}$ exhibited a negligible activity in xylose conversion whereas $\mathrm{TiO}_{2}$-A led to an important conversion of xylose (Figure 5 ) and to the formation of various by-products, some of them corresponding to the products obtained with $\mathrm{Ru} / \mathrm{TiO}_{2}-\mathrm{A}$. This point will be discussed in detail below.

By comparison, blank experiments without any solid catalyst nor support gave only a negligible level of conversion at $120^{\circ} \mathrm{C}$ after $4 \mathrm{~h}$ (less than $10 \%$ ).

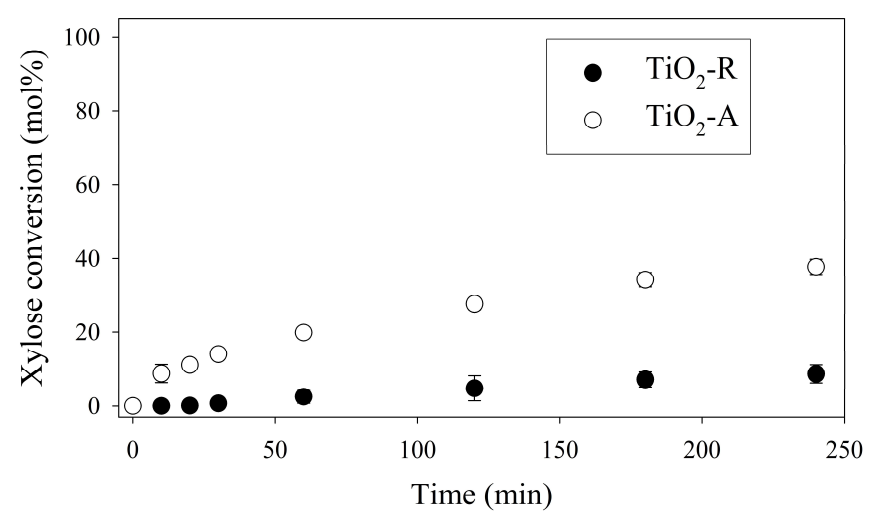

Figure 5. Xylose hydrogenation over $\mathrm{TiO}_{2}-\mathrm{R}$ and $\mathrm{TiO}_{2}-\mathrm{A}$. Reaction conditions: $120^{\circ} \mathrm{C}, 40$ bar $\mathrm{H}_{2}, 0.33 \mathrm{M}$ xylose.

\section{Effect of temperature on xylose hydrogenation}

The effect of temperature on catalytic performances was investigated for both catalysts between $100^{\circ} \mathrm{C}$ and $140^{\circ} \mathrm{C}$ (Figure 6). For $\mathrm{Ru} / \mathrm{TiO}_{2}-\mathrm{R}$, an increase in temperature led to an increase in xylose conversion rate and xylitol selectivity remained unchanged and superior to $90 \mathrm{~mol} \%$, whatever the temperature. For $\mathrm{Ru} / \mathrm{TiO}_{2}-\mathrm{A}$, an increase in temperature led to an increase in xylose conversion but also to a sharp decrease in xylitol selectivity. This indicates the predominance of sidereactions at high temperatures with $\mathrm{Ru} / \mathrm{TiO}_{2}-\mathrm{A}$ catalyst. 
a)

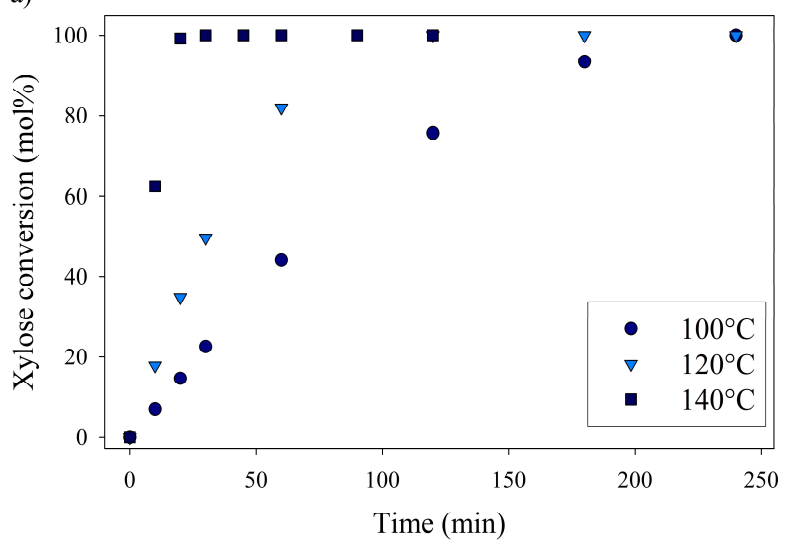

c)

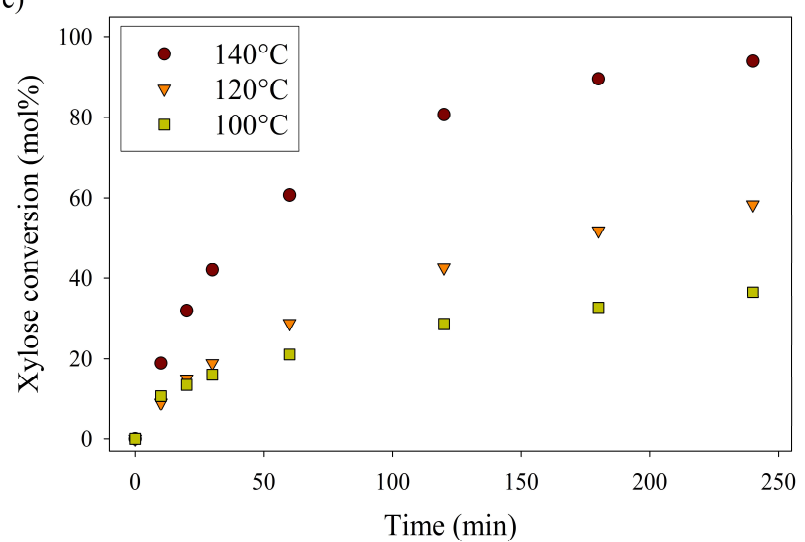

b)

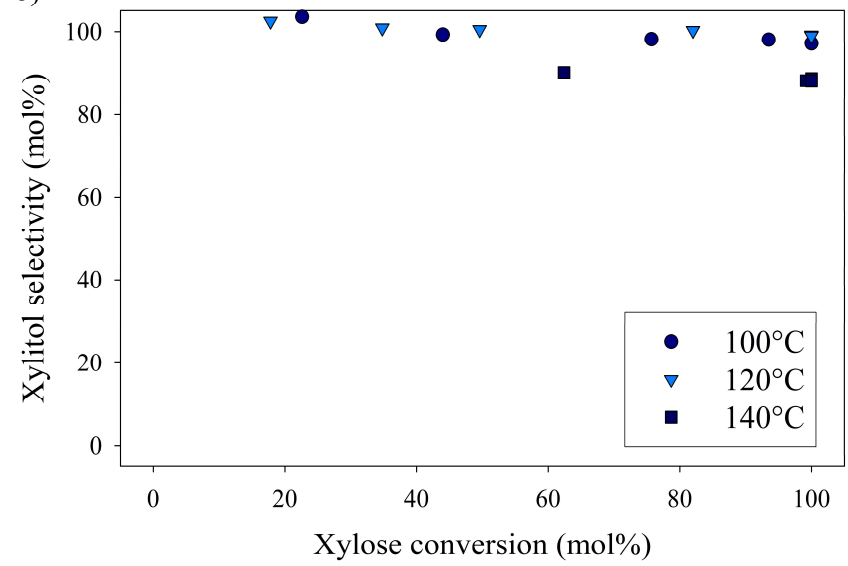

d)

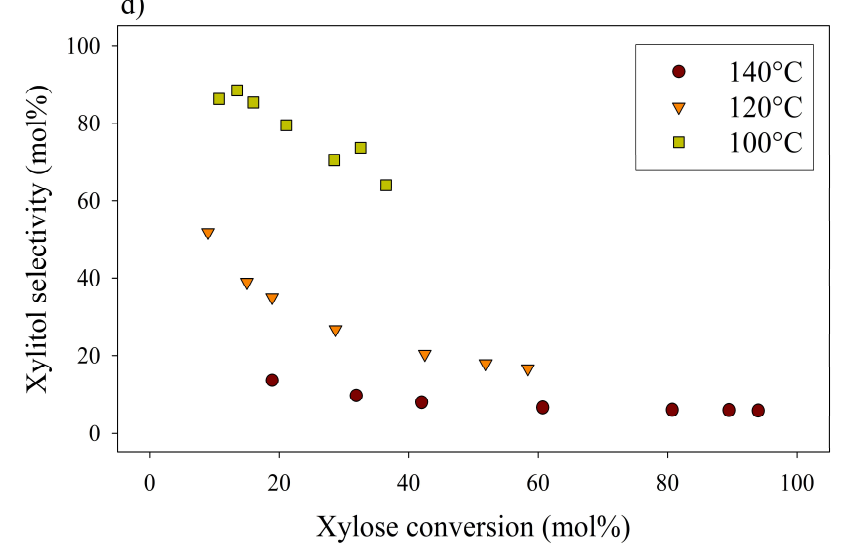

Figure 6. Effect of temperature during xylose hydrogenation over $\mathrm{Ru} / \mathrm{TiO}_{2}-\mathrm{R}$ on xylose conversion (a) and on xylitol selectivity (b) and over $\mathrm{Ru} / \mathrm{TiO}{ }_{2}-\mathrm{A}$ on $\mathrm{xylose}$ conversion (c) and on xylitol selectivity (d). Reaction conditions: $100-140^{\circ} \mathrm{C}, 40$ bar $\mathrm{H}_{2}, 0.33 \mathrm{M}$ xylose, molar ratio $\mathrm{Ru} / \mathrm{xylose} 0.45 \%$.

Formation of by-products during xylose hydrogenation over $\mathrm{Ru} / \mathrm{TiO}_{2}-\mathrm{A}$

Numerous by-products were observed on HPLC chromatograms when $\mathrm{Ru} / \mathrm{TiO}_{2}-\mathrm{A}$ was used as a catalyst (see ESI, Figure S2). Xylulose, lyxose, ribulose, arabitol and ribitol were identified during xylose hydrogenation on $\mathrm{Ru} / \mathrm{TiO}_{2}-\mathrm{A}$ and $\mathrm{TiO}_{2}-\mathrm{A}$ alone. Ribose and arabinose were not detected. The evolution of xylose conversion products with $\mathrm{Ru} / \mathrm{TiO}_{2}-\mathrm{A}$ catalyst is represented on Figure 7a. Xylulose and lyxose are isomer and epimer of xylose, respectively. Ribulose can be formed by epimerisation of the $\mathrm{C} 3$ carbon on xylulose. 
a)

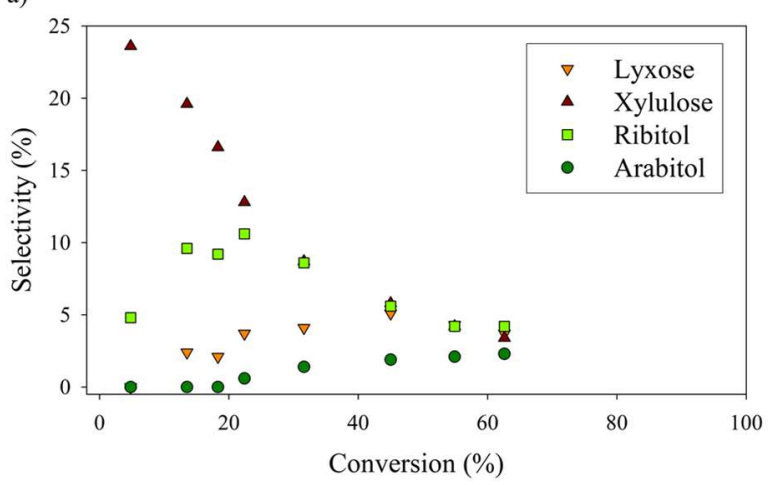

b)

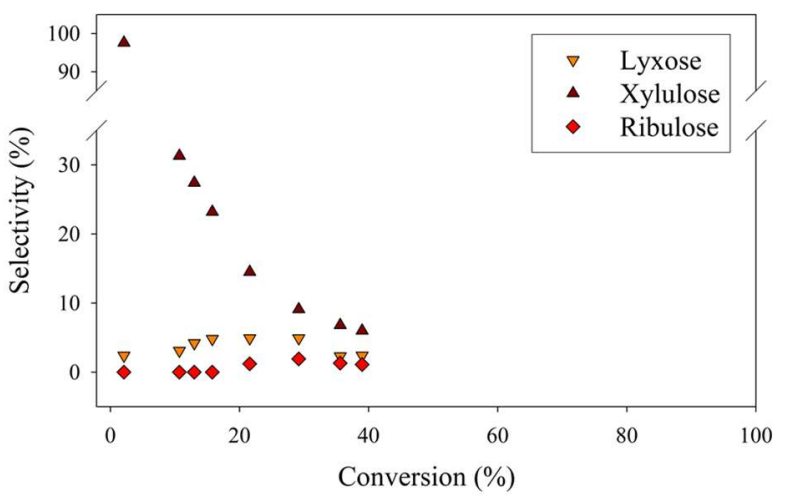

Figure 7. By-products molar selectivities during xylose hydrogenation over $\mathrm{Ru} / \mathrm{TiO}_{2}-\mathrm{A}$ (a) and $\mathrm{TiO}_{2}-\mathrm{A}$ alone (b). Reaction conditions: $120^{\circ} \mathrm{C}, 40$ bar $\mathrm{H}_{2}, 0.33 \mathrm{M}$ xylose, molar ratio $R u / x y l o s e 0.45 \%$.

When $\mathrm{TiO}_{2}-\mathrm{A}$ alone was used as a catalyst, xylulose was formed selectively at the very beginning of the reaction, and then converted into other products (Figure 7b). Lyxose was formed as a secondary product, most probably by isomerisation from xylulose, even if a small contribution of direct epimerisation from xylose cannot be discarded. Ribulose was observed in minor amount after $1 \mathrm{~h}$ of reaction, most probably from xylulose. All pentoses also seem to degrade into other products over the course of reaction. When $\mathrm{Ru} / \mathrm{TiO}_{2}-\mathrm{A}$ was used as catalyst, xylulose is also present with a high selectivity at the beginning of the reaction, and lyxose as a secondary product when conversion increases. However, the presence of ruthenium leads to the hydrogenation of pentoses to form arabitol, from lyxose and xylulose, and ribitol, most probably from xylulose via a ribulose intermediate (Figure 8 ). Ribulose itself was not observed in this case. At high conversion, all selectivities decrease, indicating the formation of degradation products.

The interconversion of aldoses can occur through different mechanisms. In the presence of a base or a Lewis acid catalyst, isomerization of aldoses into ketoses and reversely can occur through a Lobry de Bruyn-Alberda van Ekenstein mechanism (LdB-AvE) through an enediol intermediate and an intramolecular hydrogen shift. ${ }^{45-48}$ This reaction is well known for producing fructose from glucose over Sn-BEA zeolite catalysts. ${ }^{49}$ The isomerisation of xylose into xylulose and to a lesser extent, lyxose (formed by the reverse isomerization of xylulose) as well of arabinose into ribose was also reported on $\mathrm{Sn}$-BEA zeolites or $\mathrm{Nb}_{2} \mathrm{O}_{5}$ catalysts. ${ }^{49-51}$ The direct epimerisation of xylose into lyxose (or arabinose into ribose) can also occur through a Bilik reaction with a carbon shift and a rotation of C2C3 bond. ${ }^{47}$ It was described in the presence of a Lewis acid catalyst and a complexation agent (e.g. borate, calcium), ${ }^{52-54}$ or using molybdenum-based catalysts. ${ }^{55}$ Ti-doped zeolite was also active for isomerisation and epimerisation of glucose, the activity was attributed to $\mathrm{Ti}^{4+}$ Lewis acid sites. ${ }^{52,56}$ The temperature used for isomerisation of sugars ranges between 60 to $120^{\circ} \mathrm{C}$, which is compatible with the experimental conditions applied in our catalytic experiments.

The acidity of $\mathrm{TiO}_{2}-\mathrm{A}$ and $\mathrm{TiO}_{2}-\mathrm{R}$ was investigated above. The presence of acid sites on $\mathrm{TiO}_{2}-\mathrm{A}$ was observed and attributed to $-\mathrm{OH}$ groups and $\mathrm{Ti}^{4+}$ species on $\mathrm{TiO}_{2}$ surface. These sites are assumed responsible for isomerisation and/or epimerisation activities. As these reactions are catalysed only by Lewis acid sites, it is assumed that a large part of the acid sites detected on $\mathrm{TiO}_{2}-\mathrm{A}$ are Lewis acid sites. On the contrary, $\mathrm{TiO}_{2}-\mathrm{R}$ does not bear enough acid sites and to be active for xylose conversion into other pentoses.

Moreover, all pentoses can undergo hydrogenation to three corresponding polyols: arabitol, ribitol, xylitol, as described on Figure 8. Therefore, apparent Ru activity is not limited to xylitol production but also include ribitol and arabitol production; indeed, the overall reaction system is a complex network of parallel and consecutive reactions. Although this was not the point of this research, this result is also, to the best of our knowledge, the first report of ribitol production from ribulose over a $\mathrm{Ru} / \mathrm{TiO}_{2}$ catalyst.

Finally, it is worth noting that the carbon balance is decreasing during xylose reaction over $\mathrm{Ru} / \mathrm{TiO}_{2}-\mathrm{A}$ (reaching $68 \%$ after 240 min at $120^{\circ} \mathrm{C}$ ) or $\mathrm{TiO}_{2}-\mathrm{A}$ (reaching $57 \%$ after $240 \mathrm{~min}$ at $120^{\circ} \mathrm{C}$ ), indicating the formation of unidentified products through successive reactions (see ESI, Figure S4). This phenomenon was already described in literature (cf. ${ }^{47,50}$ ) and the degradation products were identified as glycoaldehyde, glyceraldehyde, dihydroxyacetone, and at higher temperatures lactic acid, HMF, furfural. Traces of lactic acid, acetic acid and furfural were detected in the products of xylose hydrogenation over $\mathrm{Ru} / \mathrm{TiO}_{2}-$ $A$ in our study but in amounts too low to be quantified. The formation of humins, i.e. unidentified carbonaceous compounds, is assumed and corroborated by the change in colour of the solution from colourless to light-brown. 


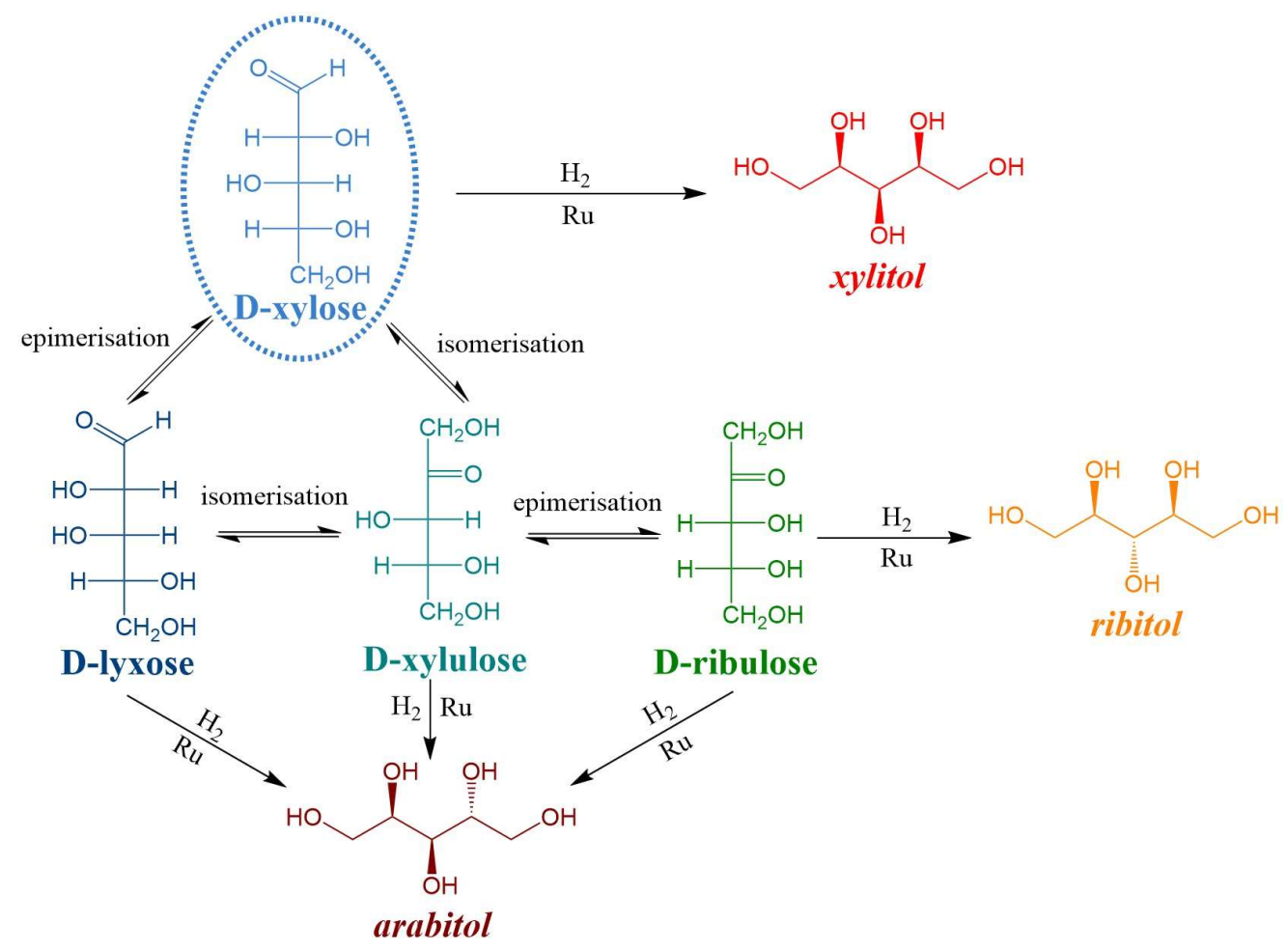

Figure 8. Reaction network during xylose hydrogenation.

\section{First approach of kinetics of sugars hydrogenation}

The detailed analysis of reaction products led to a detailed reaction mechanism (Figure 8). In this mechanism, several sugars are hydrogenated in several polyols. A basic kinetic model was built to determine simply but quantitatively the hydrogenation activity of both ruthenium catalysts (Figure 9). The model is based on a simplified mechanism were the four identified pentoses are reasonably lumped together ("sugars") as well as the three polyols products ("polyols"). Therefore, two reactions were included in the model: the hydrogenation of sugars into polyols, with a kinetic constant $\mathrm{k}_{\mathrm{H}}$, and the degradation of sugars into unknown products, $\mathrm{k}_{\mathrm{D}}$. The following hypotheses were made: i) reaction orders were assumed to be
1 for sugars and $\mathrm{O}$ for $\mathrm{H}_{2}$ (i.e. $\mathrm{H}_{2}$ concentration was assumed constant because the system is constantly fed with gaseous $\mathrm{H}_{2}$ to maintain constant $\mathrm{H}_{2}$ pressure), ii) volumes of liquid and solid were assumed constant, iii) kinetic constants are apparent pseudo-first order rate constants including a factor corresponding to the catalyst concentration. Details on kinetic modelling are given in ESI.

Figure 10 depicts the experimental results and the modelling results obtained at $120^{\circ} \mathrm{C}$ for both catalysts. A good agreement between experimental and modelling results was observed at all studied temperatures, as shown on parity plot (Figure S3 in ESI).

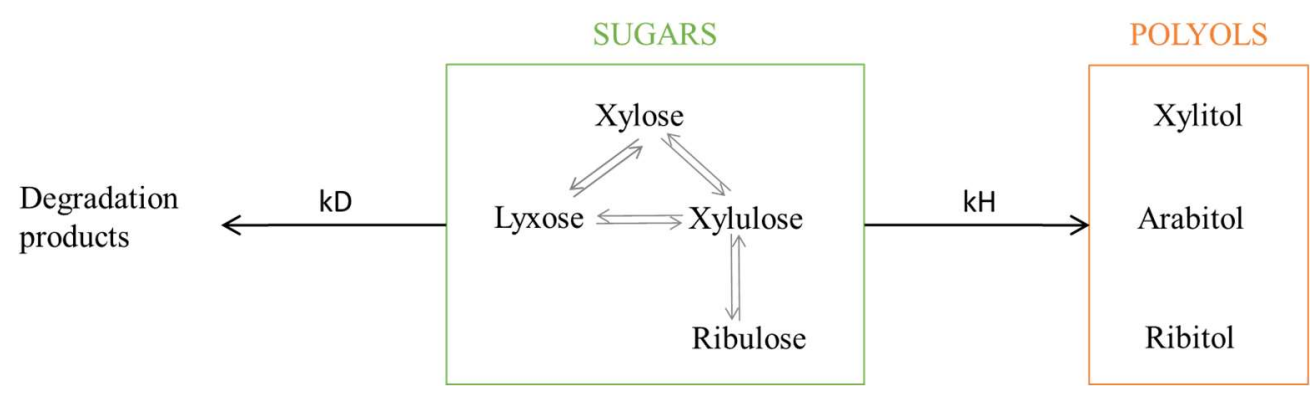



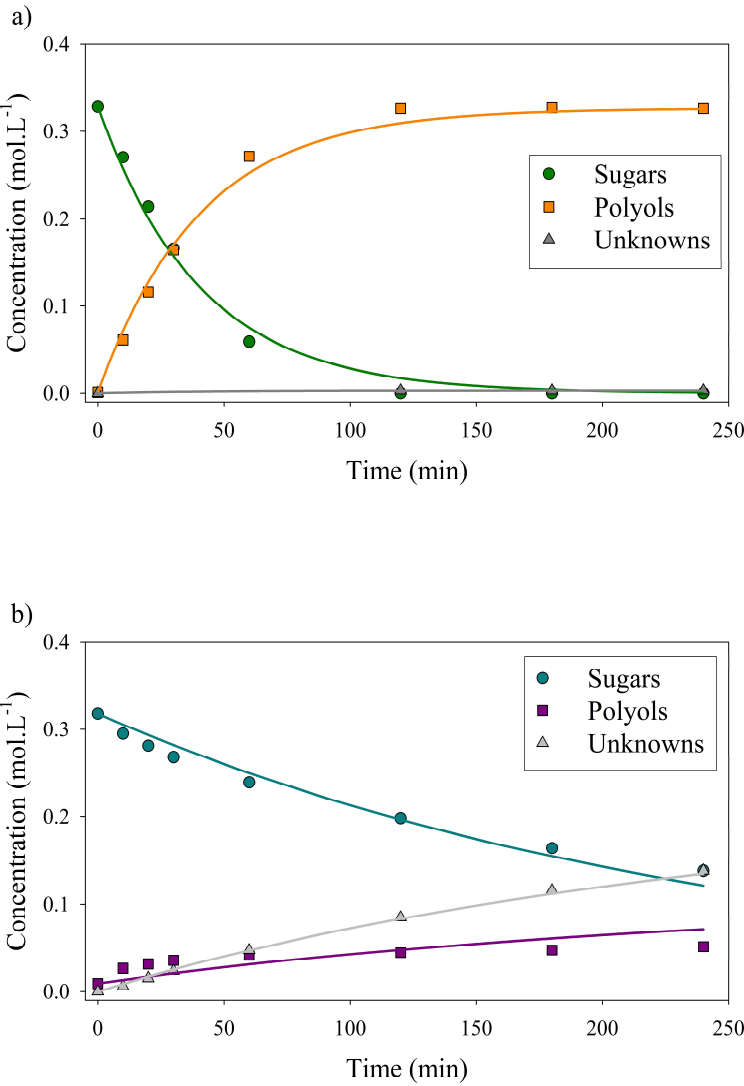

Figure 9. Concentration profiles for xylose hydrogenation over $\mathrm{Ru} / \mathrm{TiO}_{2}$ catalysts: $\mathrm{Ru} / \mathrm{TiO}_{2}-\mathrm{R}$ (a) and $\mathrm{Ru} / \mathrm{TiO}_{2}-\mathrm{A}$ (b). Dots correspond to experimental data and lines correspond to kinetic modelling data. Reaction conditions: $120^{\circ} \mathrm{C}, 40$ bar $\mathrm{H}_{2}, 0.33 \mathrm{M}$ xylose, ratio $\mathrm{Ru} / \mathrm{xylose} 0.45 \%$

At $120^{\circ} \mathrm{C}$, kinetic constant for hydrogenation rate $\mathrm{k}_{\mathrm{H}}$ was 20 times higher for $\mathrm{Ru} / \mathrm{TiO}_{2}-\mathrm{R}$ than for $\mathrm{Ru} / \mathrm{TiO}_{2}-\mathrm{A}$, resulting in a $20-$ fold increase in initial reaction rate. This illustrates the superior catalytic activity of $\mathrm{Ru} / \mathrm{TiO}_{2}-\mathrm{R}$. Kinetic constant for degradation rate $\mathrm{k}_{\mathrm{D}}$ was negligible for $\mathrm{Ru} / \mathrm{TiO}_{2}-\mathrm{R}$, which corresponds to the high selectivity for xylitol observed earlier. On the other hand, degradation rate for $\mathrm{Ru} / \mathrm{TiO}_{2}-\mathrm{A}$ was almost twice higher than hydrogenation rate, which explains the low selectivity for xylitol.

As $\mathrm{Ru} / \mathrm{TiO}_{2}-\mathrm{R}$ exhibited a higher accessibility of $\mathrm{Ru}$ atoms, its superior activity in xylose hydrogenation was expected. Turnover Frequency (TOF) values were calculated to normalize ruthenium catalytic activity by the number of surface ruthenium atoms able to activate $\mathrm{H}_{2}$ (cf ESI). TOF reaches $0.990 \mathrm{~s}^{-1}$ for $\mathrm{Ru} / \mathrm{TiO}_{2}-\mathrm{R}$ and only $0.052 \mathrm{~s}^{-1}$ for $\mathrm{Ru} / \mathrm{TiO}_{2}-\mathrm{A}$ at $120^{\circ} \mathrm{C}$, which indicates a lower activity of ruthenium catalytic sites on $\mathrm{Ru} / \mathrm{TiO}_{2}-\mathrm{A}$ (Table 3). Therefore, $\mathrm{Ru} / \mathrm{TiO}_{2}-\mathrm{A}^{\prime}$ s low activity cannot be completely explained by the low amount of accessible ruthenium atoms but also by a lower intrinsic activity of catalytic sites for hydrogenation. As a comparison, Lee et al. measured a initial TOF of $0.688 \mathrm{~s}^{-1}$ at $100^{\circ} \mathrm{C}$ for xylose hydrogenation over $3 \% \mathrm{Ru} / \mathrm{Al}_{2} \mathrm{O}_{3}{ }^{21}$ whereas our $\mathrm{Ru} / \mathrm{TiO}_{2}-\mathrm{R}$ catalyst reached $0.469 \mathrm{~s}^{-1}$ at the same temperature and similar operating conditions.
With the same methodology, TOF ${ }_{\text {deg }}$ for degradation reaction were calculated from acid sites concentration (see Table 3 ) and the initial rate of degradation reaction at $120^{\circ} \mathrm{C}$. The values obtained were $0.003 \mathrm{~s}^{-1}$ for $\mathrm{Ru} / \mathrm{TiO}_{2}-\mathrm{R}$ and $0.002 \mathrm{~s}^{-1}$ for $\mathrm{Ru} / \mathrm{TiO}_{2}-$ A. Therefore, the degradation activity per acid sites is similar for both catalysts. The high selectivity for degradation products in the presence of $\mathrm{TiO}_{2}-\mathrm{A}$ is thus a consequence of its large specific surface area.

Activation energies were calculated following the Arrhenius law (see ESI). For $\mathrm{Ru} / \mathrm{TiO}_{2}-\mathrm{R}$, activation energy determined from hydrogenation rate was $83.7 \mathrm{~kJ} . \mathrm{mol}^{-1}$. In literature, activation energies for xylose hydrogenation vary from $32 \mathrm{~kJ}^{\mathrm{mol}} \mathrm{m}^{-1}$ (over

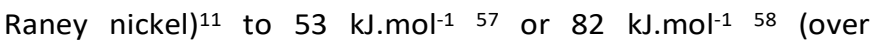
ruthenium). Our results are in accordance with the values reported. For $\mathrm{Ru} / \mathrm{TiO}_{2}-\mathrm{A}$, activation energy determined from hydrogenation rate was $18.5 \mathrm{~kJ}^{\mathrm{mol}}{ }^{-1}$, indicating a mechanism different for polyols production, in accordance with the reaction network shown on Figure 8, and activation energy determined from degradation rate was $106.2 \mathrm{~kJ} . \mathrm{mol}^{-1}$. These values of Ea are consistent with the low xylitol selectivity at $140^{\circ} \mathrm{C}$ observed for $\mathrm{Ru} / \mathrm{TiO}_{2}-\mathrm{A}$ (Figure 6): at high temperature, degradation is favoured over hydrogenation, whereas at low temperature, xylitol production is favoured over sugars degradation.

Table 3. Kinetic parameters - sugars hydrogenation.

\begin{tabular}{|c|c|c|}
\hline & $\mathrm{Ru} / \mathrm{TiO}_{2}-\mathrm{R}$ & $\mathrm{Ru} / \mathrm{TiO}_{2}-\mathrm{A}$ \\
\hline $\begin{array}{l}\text { Kinetic constant / Hydrogenation } \mathbf{k}_{\mathrm{H}, 120^{\circ} \mathrm{C}} \\
\qquad\left(10^{3} \mathrm{~min}^{-1}\right)\end{array}$ & 24.4 & 1.3 \\
\hline $\begin{array}{l}\text { Initial TOF / Hydrogenation } \text { TOF }_{0,120^{\circ} \mathrm{C}} \\
\qquad\left(\mathrm{s}^{-1}\right)\end{array}$ & 0.990 & 0.052 \\
\hline $\begin{array}{l}\text { Kinetic constant / Degradation } \mathbf{k}_{\mathrm{D}, 120^{\circ} \mathrm{C}} \\
\qquad\left(10^{3} \mathrm{~min}^{-1}\right)\end{array}$ & 0.22 & 2.8 \\
\hline $\begin{array}{l}\text { Initial TOF / Degradation TOF }{ }_{\mathrm{DEG} 0,120^{\circ} \mathrm{C}} \\
\qquad\left(\mathrm{s}^{-1}\right)\end{array}$ & 0.003 & 0.002 \\
\hline $\begin{array}{l}\text { Activation energy / Hydrogenation } \\
\left(\mathrm{kJ} . \mathrm{mol}^{-1}\right)\end{array}$ & 83.7 & 18.5 \\
\hline $\begin{array}{l}\text { Activation energy / Degradation } \\
\left(\mathrm{kJ} \cdot \mathrm{mol}^{-1}\right)\end{array}$ & 147.9 & 106.2 \\
\hline
\end{tabular}

Detailed calculation of k, TOF and Ea are presented in ESI.

In summary, the support $\mathrm{TiO}_{2}-\mathrm{A}$ is responsible for two phenomena in xylose reactivity:

i) A decrease in xylose conversion, i.e. a decrease in catalytic activity, which is linked with a decrease in ruthenium sites active for hydrogenation;

ii) A decrease in xylitol selectivity, which corresponds to the formation of by-products through undesired reactions and therefore to the presence of different catalytic sites on the support.

Therefore, contrary to the study of Hernandez-Mejia et al. on $\mathrm{Ru} / \mathrm{TiO}_{2}$ support effects during xylose hydrogenation, ${ }^{27}$ we attribute the higher activity and selectivity of $\mathrm{Ru} / \mathrm{TiO}_{2}-\mathrm{R}$ not to the presence of smaller Ru nanoparticles but rather to the higher ability of ruthenium active sites to activate $\mathrm{H}_{2}$ on $\mathrm{Ru} / \mathrm{TiO}_{2}-\mathrm{R}$. 


\section{Conclusions}

The role of $\mathrm{TiO}_{2}$ support in the hydrogenation of xylose over $\mathrm{Ru} / \mathrm{TiO}_{2}$ catalysts was investigated by preparing $\mathrm{Ru}$ catalysts with two different $\mathrm{TiO}_{2}$ materials: an anatase $\mathrm{TiO}_{2}$ support with a large specific surface area, large pore volume and medium surface acidity, and a rutile $\mathrm{TiO}_{2}$ support without porosity and negligible surface acidity.

The synthesis of $\mathrm{Ru} / \mathrm{TiO}_{2}$ catalysts from these two supports gave two different catalytic materials: $\mathrm{Ru} / \mathrm{TiO}_{2}-\mathrm{R}$ bears large ruthenium nanoparticles in weak interaction with $\mathrm{TiO}_{2}$ support, whereas $\mathrm{Ru} / \mathrm{TiO}_{2}-\mathrm{A}$ bears small ruthenium particles in strong interaction with $\mathrm{TiO}_{2}$ support.

Whereas one would expect that small, well-dispersed nanoparticles would result in higher catalytic activity for hydrogenation reaction, the opposite happened. $\mathrm{Ru} / \mathrm{TiO}_{2}-\mathrm{A}$ was less efficient to activate $\mathrm{H}_{2}$, as evidenced by chemisorption measurements. It was also less active for xylose hydrogenation, with initial hydrogenation TOF 20 times slower than for $\mathrm{Ru} / \mathrm{TiO}_{2}-$ R. This lack of activity was attributed to strong metal support interactions between small ruthenium nanoparticles and $\mathrm{TiO}_{2}$ anatase support.

Moreover, the selectivity of the reaction is also impacted by the type of support. $\mathrm{Ru} / \mathrm{TiO}_{2}-\mathrm{R}$ led to a xylitol selectivity close to 100 $\%$ at all studied temperatures. In presence of $\mathrm{Ru} / \mathrm{TiO}_{2}-\mathrm{A}$ xylitol selectivity decreased with conversion. The low selectivity in presence of $\mathrm{TiO}_{2}$ anatase was explained by the formation of multiple by-products on $\mathrm{TiO}_{2}$ catalytic sites, including several pentoses isomers of xylose: xylulose, lyxose, ribulose, and the corresponding polyols: arabitol, ribitol. The presence of Lewis acid sites on $\mathrm{TiO}_{2}$ surface is assumed responsible for this particular reactivity.

In conclusion, $\mathrm{TiO}_{2}$ support plays an important role in the reactivity of $\mathrm{Ru} / \mathrm{TiO}_{2}$ catalysts. It has been demonstrated that $\mathrm{TiO}_{2}$ rutile, even with a small specific surface area, is the best option for xylitol production. Alternatively, Even if $\mathrm{TiO}_{2}$ anatase present textural properties can compatible with better active phase dispersion, it also produces various pentoses and polyols from a single sugar, xylose due to its acidic character. This work underlines the importance of choice of support in metalsupported catalysis and for its appropriate and fine characterization.

Although the formation of xylose isomers and polyols is due to serendipity, it can represent a new approach in the synthesis of rare sugars and rare polyols from available resources. We present here a new reactivity of $\mathrm{TiO}_{2}$, which is a simple, robust and commercial material, as an alternative for the production of xylulose and lyxose from xylose. Moreover, the production of ribitol and arabitol from these pentoses was also evidenced in the presence of ruthenium.

\section{Author Contributions}

L. Vilcocq: Conceptualisation; Funding acquisition; Investigation; Project administration; Supervision; Visualisation; Writing - original draft. A.M. Paez: Investigation; Visualisation. V.D.S. Freitas: Investigation; Writing - review \& editing. L. Veyre: Investigation; Visualisation. R. Philippe:
Supervision; Writing - review \& editing. P. Fongarland: Supervision; Writing - review \& editing.

\section{Conflicts of interest}

There are no conflicts to declare.

\section{Acknowledgements}

Ruben Vera (CDHL) is acknowledged for his assistance on XRD analysis. Antoinette Boréave (IRCELYON) is thanked for her help on TPR analysis. Stéphanie Pallier (LGPC/CP2M) is acknowledged for her assistance on solid characterizations. Laurent Djakovitch, Noémie Perret and Antonio Hernandez Mañas (IRCELYON) are thanked for their help in FTIR analysis and HPLC analysis. Alain Favre-Réguillon is acknowledged for scientific discussion.

This work was supported by National Research Agency (ANR) with the funding of project CHICHE (ANR-18-CE43-0004). The authors thank Axelera cluster for the chemical and environmental sectors.

\section{Notes and references}

1 Y. Panchaksharam, P. Kiri, A. Bauen, C. vom Berg, Á. Puente, R. Chinthapalli, J. Spekreijse, J. Vos, S. Pfau, K. Rübberdt, J. Michels and L. König, Roadmap for the Chemical Industry in Europe towards a Bioeconomy, 2019.

2 S. V. Vassilev, D. Baxter, L. K. Andersen, C. G. Vassileva and T. J. Morgan, Fuel, 2012, 94, 1-33.

3 I. Delidovich, K. Leonhard and R. Palkovits, Energy Environ. Sci., 2014, 7, 2803.

4 C. K. Yamakawa, F. Qin and S. I. Mussatto, Biomass and Bioenergy, 2018, 119, 54-60.

5 A. Ebringerová, Z. Hromádková and T. Heinze, in Polysaccharides I, ed. T. Heinze, Springer-Verlag, Berlin/Heidelberg, 2005, vol. 186, pp. 1-67.

6 H. V. Scheller and P. Ulvskov, Annu. Rev. Plant Biol., 2010, 61, 263-289.

7 T. Werpy and G. Petersen, Top Value Added Chemicals from Biomass, 2004.

8 J. J. Bozell and G. R. Petersen, Green Chem., 2010, 12, 539.

9 Research and Markets, Xylitol Market: Global Industry Trends, Share, Size, Growth, Opportunity and Forecast 2018-2023, 2018.

10 E. Moreni, Patent FR2631831A1, 1989.

11 J. Wisniak, M. Hershkowitz, R. Leibowitz and S. Stein, Ind. Eng. Chem. Prod. Res. Dev., 1974, 13, 75-79.

12 I. S. M. Rafiqul and A. M. M. Sakinah, Food Rev. Int., 2013, 29, 127-156.

13 Y. Delgado Arcaño, O. D. Valmaña García, D. Mandelli, W. A. Carvalho and L. A. Magalhães Pontes, Catal. Today, 2020, 344, 2-14.

14 M. Yadav, D. K. Mishra and J. Hwang, Appl. Catal. A Gen., 2012, 425-426, 110-116.

15 R. Morales, C. H. Campos, J. L. G. Fierro, M. A. Fraga and G. Pecchi, Catal. Today, 2018, 310, 59-67. 

T. Heil, M. Antonietti and M. Al-Naji, Green Chem., 2020, 22, 2755-2766. H. Xia, L. Zhang, H. Hu, S. Zuo and L. Yang, Nanomaterials, 2019, 10, 73.

A. P. Tathod and P. L. Dhepe, Green Chem., 2014, 16, 4944-4954.

R. Morales, C. H. Campos, J. L. G. Fierro, M. A. Fraga and G. Pecchi, Mol. Catal., 2017, 436, 182-189. C. Michel, J. Zaffran, A. M. Ruppert, J. Matras-Michalska, M. Jędrzejczyk, J. Grams and P. Sautet, Chem. Commun., 2014, 50, 12450-12453. J. Lee, Y. Xu and G. W. Huber, Appl. Catal. B Environ., 2013, 140-141, 98-107. Chem., 2014, 16, 645-652. J.-P. Lange, Angew. Chemie Int. Ed., 2015, 54, 13186 13197.

J. Zhang, L. Pei, J. Wang, P. Zhu, X. Gu and Z. Zheng, Catal. Sci. Technol., 2020, 10, 1518-1528. A. Romero, E. Alonso, Á. Sastre and A. Nieto-Márquez, Microporous Mesoporous Mater., 2016, 224, 1-8. D. K. Mishra, J. M. Lee, J. S. Chang and J. S. Hwang, Catal. Today, 2012, 185, 104-108.

C. Hernandez-Mejia, E. S. Gnanakumar, A. Olivos-Suarez, J. Gascon, H. F. Greer, W. Zhou, G. Rothenberg and N. Raveendran Shiju, Catal. Sci. Technol., 2016, 6, 577-582. F. Liu, J. Ftouni, P. C. A. Bruijnincx and B. M. Weckhuysen, ChemCatChem, 2019, 11, 2079-2088. A. Kim, D. P. Debecker, F. Devred, V. Dubois, C. Sanchez and C. Sassoye, Appl. Catal. B Environ., 2018, 220, 615625. Michalska, N. Keller, K. Ostojska and P. Sautet, ChemSusChem, 2015, 8, 1538-1547. K. Yu, N. Kumar, A. Aho, J. Roine, I. Heinmaa, D. Y. Murzin and A. Ivaska, J. Catal., 2016, 335, 117-124. G. Gran, H. Dahlenborg, S. Laurell and M. Rottenberg, Acta Chem. Scand., 1950, 4, 559-577.
G. Gran, Int. Congr. Anal. Chem., 1952, 77, 661-671.

R. Berthoud, P. Délichère, D. Gajan, W. Lukens, K. Pelzer, J.M. Basset, J.-P. Candy and C. Copéret, J. Catal., 2008, 260, 387-391.

M. Thommes, K. Kaneko, A. V. Neimark, J. P. Olivier, F. Rodriguez-Reinoso, J. Rouquerol and K. S. W. Sing, Pure Appl. Chem., 2015, 87, 1051-1069.

G. Lodi, L. A. Pellegrini, A. Aliverti, B. Rivas Torres, M. Bernardi, M. Morbidelli and G. Storti, J. Chromatogr. A, 2017, 1496, 25-36.

T. C. Laurent and J. Killander, J. Chromatogr. A, 1964, 14, 317-330.

A. Mahdavi-Shakib, S. Husremovic, S. Ki, J. Glynn, L. Babb, J. Sempel, I. Stavrinoudis, J.-M. Arce-Ramos, R. Nelson, L. C. Grabow, T. J. Schwartz, B. G. Frederick and R. N. Austin, Polyhedron, 2019, 170, 41-50.

S. Musić, M. Gotić, M. Ivanda, S. Popović, A. Turković, R. Trojko, A. Sekulić and K. Furić, Mater. Sci. Eng. B, 1997, 47, 33-40.

M. Primet, P. Pichat and M. V. Mathieu, J. Phys. Chem., 1971, 75, 1216-1220.

M. V. Mathieu, M. Primet and P. Pichat, J. Phys. Chem., 1971, 75, 1221-1226. 